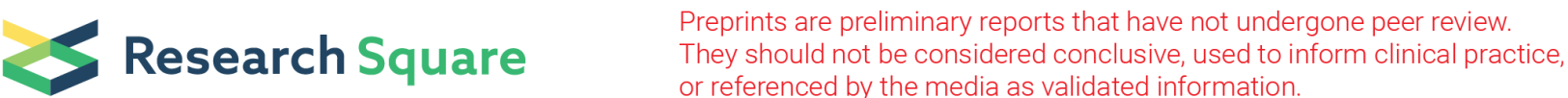

\section{Characterization and Critical Appraisal of Physiotherapy Intervention Research in Nigeria: A Systematic Review}

Martins Nweke ( $\square$ martins.nweke@gmail.com )

University of Pretoria https://orcid.org/0000-0002-9493-9443

\section{Emeriewen Ejiroghene}

University of Benin

Henrietta. O. Fawole

University of Benin

Mshunqane Nombeko

University of Pretoria

\section{Research}

Keywords: Physiotherapy, clinical research, characterization, appraisal, Nigeria.

Posted Date: December 20th, 2021

DOI: https://doi.org/10.21203/rs.3.rs-1141258/v1

License: (c) (i) This work is licensed under a Creative Commons Attribution 4.0 International License. Read Full License 


\section{Abstract \\ Objectives}

Clinical research is the bedrock of clinical innovation, education and practice. We characterized and critically appraised physiotherapy clinical research to avoid implementing misleading research findings into practice and to task the Nigerian physiotherapy societies on responsible conduct of clinical research.

\section{Methods}

This is a systematic review of articles published in English between 2009 and 2021. We searched Pubmed, Medline, Cumulative Index to Nursing and Allied Health Literature, Academic Search Complete, PsycINFO and African Journal Online, and reference lists of relevant articles. Data were selected and extracted according to predesigned eligibility criteria and using a standardized data extraction table. Where appropriate, the Pedro and Cochrane ROBINS1 were used to examine the risk of bias.

\section{Results}

Of the clinical experiments, the randomized controlled trial (RCT) was the most common design (87.5\%). Musculoskeletal conditions (39.3\%) were the most studied disorder. Most of the studies (76.8\%) were of suboptimal quality. Interventions constituted exercise therapy (76.3\%), manual therapy (8.5\%) and electrotherapy (8.5\%). More than half $(67.8 \%)$ of the studies recorded medium to large effect sizes. A fair proportion $(48.2 \%)$ of the studies had a confounding-by-indication bias. A few studies conducted normality tests (10.9\%) and intention-to-treat analysis (37.5\%).

\section{Discussion}

Of the clinical research, the volume of clinical experiments in the Nigeria Physiotherapy research community is small; notwithstanding, RCT is the most frequent clinical experiment. Physiotherapy interventions especially exercise appears effective, although incongruence between effect size and study quality limits inference. Sources of bias include absent/inadequate covariate analysis, blinding and intention-to-treat analysis approach.

\section{Registration:}

We registered the protocol with PROSPERO. The registration number: CRD42021228514.

\section{Introduction}


Clinical research is the bedrock of clinical innovation, education and practice in both developed and developing nations. ${ }^{1}$ Without it, there can be no advancement in health and clinical practice, and philosophy, opinions, mere assumptions and quackery will occupy the front rows in the care for the whole man. ${ }^{2}$ The competitive search for the Coronavirus-19 vaccine through clinical inquiries illustrates the typical role of clinical research in health development and innovation. ${ }^{3}$ The role of clinical research is multifaceted and cannot be overemphasized. It provides information about disease trends and risk factors, outcomes of treatment, public health intervention, functional abilities, patterns of care, health care costs amongst others. ${ }^{4}$ Health research has led to the development of new therapies, and remarkable improvement in health care and public health. ${ }^{5}$ They form the primary means by which a nation's healthcare goals are achieved and improved. ${ }^{6}$ Interestingly, no therapy, testing procedure or clinical device is deemed safe and effective for public consumption except by evidence emerging from clinical research. ${ }^{7}$

Physiotherapy education is over 50years in Nigeria, ${ }^{8}$ however, evidence emerging from an Ibadan-based study reveals a low level of participation in clinical research among Nigerian Physiotherapists, ${ }^{9}$ with outputs negatively skewed towards non-clinical observational studies. ${ }^{10}$ While one cannot dispute the utter relevance of non-clinical research, the need for clinical and intervention research supersedes and cannot be overemphasized. ${ }^{6}$ The quality of Nigerian-based clinical research leaves much to be desired. ${ }^{11}$ This possesses implications for both implementations of science and clinical practice in a country where Physiotherapy is fast becoming a routine treatment. The overt dependency on research innovations and patency obtained in developed nations as well as poor research funding constitutes a hindrance to the development of clinical Physiotherapy in the Nigerian context. In a country hosting over $50 \mathrm{PhD}$ students every four to five years, one would expect a fair degree of innovations and growth of the Physiotherapy profession, ${ }^{12}$ with the contextualization of practice given the scarcity of resources. However, the paucity of thoroughly informed and designed interventional studies, lack of implementation of research findings and poor research funding remain the major challenges. ${ }^{11,13}$ As part of the strategy directed at the development of clinical physiotherapy education and practice in Nigeria, this review aims to characterize and critically appraise clinical interventional research in Nigeria. We aimed to set forth recommendations for relevant stakeholders and policymakers.

\section{Objectives}

The primary objective of this review was to characterise and appraise physiotherapy intervention research in Nigeria. Secondarily, the review sought to evaluate the over-arching efficacy of physiotherapy interventions as represented in Nigeria clinical research.

\section{Methods}

\section{Protocol and registration}


This systematic review followed the Preferred Reporting Items for Systematic Reviews (PRISMA) checklist, which was supplemented by the Joana Briggs Institute Scoping Review Guidelines. ${ }^{14}$ The protocol is registered with PROSPERO, ID- CRD42021228514.

\section{Eligibility Criteria}

Studies involving a Nigerian patient population were included, as were studies examining the effect of a physiotherapeutic intervention in a Nigerian patient population. We included research regardless of whether or not a comparator was employed. We also considered trials that included a pharmaceutical comparator but provided enough information to determine the physiotherapy intervention modality's independent effect. The outcomes constitute study characteristics (including design, sample size, intervention and disease studied), methodological quality, study effect size and power. We included articles written and published in English between 2009 and 2021. Studies were included irrespective of setting (primary, secondary, tertiary health care, private physiotherapy clinics/gym centres). We excluded studies conducted before 2009 or mixed studies in which it is difficult to ascertain the stand-alone effect of a physiotherapeutic intervention.

\section{Information source}

In line with the registered review protocol, we searched for original research articles and systematic reviews using PubMed, Cochrane Library, MEDLINE, CINAHL, Academic Search Complete, PsycINFO and African Journal Online. Furthermore, we searched the reference lists of relevant articles for additional peer-reviewed articles.

\section{Search}

Initially, we harvested keywords and MeSH terms from key articles. We then analysed the keywords and index terms used to describe the articles. We conducted a pilot search using these terms in PubMed. We refined the search terms to obtain the most sensitive and specific strategy (See Appendix 1). A third search using the piloted terms was conducted across all selected databases. The earliest search was carried in January 2021 while the latest search was done using AJOL in June 2021.

\section{Study selection}

We exported our search results directly into EndNote 8, where duplicate articles were removed. Once all the duplicate articles were removed, a reviewer screened the titles and selected articles that met the inclusion criteria. EE reviewed the full-text articles and excluded articles that did not meet the eligibility criteria under the supervision of NM. We screened the reference lists of relevant articles to identify additional studies. We did not restrict studies based on target population, setting, neuropsychological test used or language. We only included studies published after 2009. We only included studies published in English. We excluded case reports to enhance comparability. The PRISMA diagram details the flow of studies throughout the selection process, along with reasons for excluding articles (Figure 1). 


\section{Data collection process}

In this review, data were extracted by EE and validated by NM. From each article, we extracted primary data including study characteristics (design, intervention and disease) and study quality. We also extracted data necessary to estimate the study effect size and post-hoc study power. We also recorded article information including author, title, population, sample size, sampling techniques, geopolitical region and summary of findings. Data were extracted using a custom spreadsheet. We contacted a study author to ask for full-text details.

\section{Data items}

Primary data sought included study characteristics (design, sample size, intervention utilised, and disease condition), and study quality. Secondary data were age, sex, mean difference and summary of findings.

\section{Risk of bias assessment and quality Appraisal}

We undertook quality appraisal using the Pedro Risk of Bias Assessment Tool Scale and Cochrane ROBINS-1, depending on the design. The Pedro scale is a specialized and reliable methodological evaluation instrument for physiotherapy RCTs. ${ }^{15}$ Only when a requirement is met is a point awarded. The reliability of Pedro scale item evaluations ranged from "fair" to "significant," while the entire Pedro score's reliability was "fair" to "good". ${ }^{15}$ The measure appears to be reliable enough to be used in systematic evaluations of RCTs in physical therapy. ${ }^{15}$ In this study, we defined optimal study quality as Pedro score $\geq 7$. Similarly, the Cochrane ROBINS 1 is the most commonly recommended tool for non-randomized clinical experiments. ${ }^{16}$

\section{Summary measure and data synthesis}

We obtained mean difference from studies and computed effect size per study, in line with Borenstein et al. ${ }^{17}$ and Lenhard ${ }^{18}$. Post-hoc power was computed using the G-power software. Alpha was set at 0.05. For confounding-by-indication, we assessed studies for analysis of baseline comparison for sociodemographic and the key outcome. The assessment was scored over 5,6 or 7 depending on the disorder. Age, gender, BMI and occupation (rarely) were the prevalent socio-demographics assessed (Table 1).

Table 1: Determination of confounding-by-indication bias 


\begin{tabular}{|llll|}
\hline S/N & Disorder & Confounds & $\begin{array}{c}\text { Pass-score } \\
\text { including KO }\end{array}$ \\
\hline 1 & $\begin{array}{l}\text { Breast } \\
\text { cancer }\end{array}$ & Age, medication, BMI, KO & $2 / 4$ \\
\hline 2 & $\begin{array}{l}\text { Cerebral } \\
\text { palsy }\end{array}$ & Age, severity, KO & $2 / 3$ \\
\hline 3 & COPD & Age, gender, respiratory rate, KO & $2 / 4$ \\
\hline 4 & Diabetes & Age, BMl, gender, KO & $2 / 4$ \\
\hline 5 & Heart failure & Age, gender, Heart rate, KO & $2 / 4$ \\
\hline 6 & HIV & $\begin{array}{l}\text { Age, gender, viral load/CD4 counts, adherence to drugs, } \\
\text { depression, KO }\end{array}$ & $3 / 6$ \\
\hline 7 & Hypertension & Age, gender, BMI, diabetes, KO & $2 / 5$ \\
\hline 8 & LBP & Age, gender, BMI, occupation, KO & $2 / 5$ \\
\hline 9 & Lumbar rad. & Age, gender, BMl, occupation, KO & $2 / 5$ \\
\hline 10 & Menopause & Age, gender, BMl, peri/post variations, KO & $2 / 5$ \\
\hline 11 & Obesity & Age, gender, BMl, KO & $2 / 4$ \\
\hline 12 & Osteoarthritis & Weight, BMI, age, gender, occupation, KO & $3 / 6$ \\
\hline 13 & SCA & Age, gender, BMl, baseline Hb, KO & $2 / 5$ \\
\hline 14 & Stroke & Age, gender, BMl, severity, time, type of stroke, laterality. & $3 / 6$ \\
\hline 15 & $\begin{array}{l}\text { NS- Neck } \\
\text { pain }\end{array}$ & Age, gender, BMl, occupation, KO & $2 / 5$ \\
\hline
\end{tabular}

KO: Key outcome, COPD: Chronic obstructive pulmonary disease; BMI: Body mass index; HIV: Human immunodeficiency virus; Hb: hemoglobin, LBP: Low back pain; SCA: Sickle Cell Anemia; NS: Non specific

\section{Results}

\section{Study selection and characteristics}

We identified 2800 records. After de-duplication, 1990 records remained. After screening all the titles and abstracts, we excluded 1858 irrelevant records, leaving 132 records for full-text review. Of the 132 fulltexts, 86 publications were excluded. Ultimately, our review included 56 articles involving 4554 participants from six geopolitical regions of the country (Figure 1). Of the included studies, 1 (2\%) was done in North-Central, 3 (6.5\%) in North-East, 13 (23.9\%) in North-West, 4 in South-East (7\%), 1(2\%) in South-South, 33 (59\%) in South-West, and 1(2\%) in both South-South and South-West. The included studies were published between 2010 and 2021. 


\section{Participants' characteristics}

The mean age of the participants was $44.7 \pm 6.97$ years ( $41.73 \pm 8.44$ years and $47.69 \pm 5.5 y e a r s)$ for the experimental group and control groups, respectively. The male to female for the experimental and control group ratio was 1.1:1 and 1.2:1 respectively. Most of the studies did not report educational backgrounds but amongst studies (five) that did, the average percentage of participants with less than secondary education was $23.5 \%$ while $77 \%$ for the experiment group that had above secondary education.

\section{Quality Appraisal}

Of the 56 studies, we assessed the quality of the 49 RCTs using Pedro. Thirteen (23.2\%) studies were found to be optimal, while $43(76.8 \%)$ were of suboptimal quality. All the seven non-randomised experiments assessed using ROBINS-1 had a low risk of bias.

\section{Disorders, interventions and outcomes}

A total of 17 disorders were studied. These include non-specific spinal pain $13(25 \%)$, type 2 diabetes mellitus(DM) 9 (16.1\%), hypertension 8(13.6\%), osteoarthritis 7(12.5\%) and HIV infection 5(8.9\%), among others. The interventions utilized were exercises $45(76.3 \%)$, manual therapy $5(8.5 \%)$, electrotherapy 5 (8.5\%) etc. Types of exercise were stabilization exercises, therapeutic exercise, aerobic exercises, mobilization exercise, resistance exercise, aquatic exercise, walking, McKenzie back exercise, isometric handgrip exercise etc. The three most studied key outcomes were pain intensity $17(28.8 \%)$, blood pressure 11 (18.6\%) and blood glucose 5 (8.5\%) (Table 3).

\section{Study Designs, Sample size, \& Sampling Techniques}

Of the 56 studies included in this review, 49 (87.5\%), 5 (8.9\%) and 2 (3.6\%) were randomized control trials, non-randomized control trials and one-group (pre-post) experiments, respectively. Regarding sample size, Onigbinde et al. ${ }^{19}$ and Lamina et al. ${ }^{20}$ utilized the least (17) and largest (324) sample sizes, respectively. Probability sampling techniques were employed in $49(87.5 \%)$ of the studies, while non-probability techniques were utilized in 7 (12.5\%) studies.

\section{Statistics and Confounding Bias}

On assessment for the test of normality of dataset, 5 (10.87\%) studies performed a normality test. Three of them ${ }^{21,22,23}$ appropriately used the Shapiro-Wilk test. Abdulahi, ${ }^{24}$ inappropriately employed Kolmogorov, while John et al. ${ }^{25}$ did not specify which type of normality test was conducted. Besides the lack of normality test, we found statistical analytical methods used in $41.3 \%$ of studies to be inappropriate, for failure to conduct additional analysis of covariates. Of the 56 included studies, 27 (48.2\%) suffered confounded-by-indication bias, 21 (37.5\%) were without confound, while 8 (14\%) had confounded-by-indication bias which was accounted for during statistical analysis. Sources of confounding bias were missing baseline comparison of relevant socio-demographic characteristics (36.8\%), missing baseline comparison of key outcome(s) (15.8\%), missing baseline comparison of both 
socio-demographic characteristics and key outcome(s) (26.3\%) and failure to account for a statistically significant difference in baseline levels of relevant outcomes in the final post-intervention analysis (21.1\%). A few studies (37.5\%) employed an intention-treat approach to statistical analysis.

\section{Study Power and Effect Size}

Regarding the magnitude of study effect, we found 8 (15.9\%) studies with no effect, 8 (15.9\%) had a small effect, 18 (31.8\%) with medium effect, and 20 (36.4\%) had with large effects (Table 3 ).

Table 3: Effect size, and statistical power of the included studies 


\begin{tabular}{|c|c|c|c|c|c|c|}
\hline$S / N$ & Author & $\begin{array}{l}\text { Intervention for outcome(tool) in } \\
\text { condition }\end{array}$ & $\begin{array}{l}\mathrm{P}- \\
\text { values }\end{array}$ & $\begin{array}{l}\text { Effect } \\
\text { size }\end{array}$ & $\begin{array}{l}\text { Power } \\
\%\end{array}$ & Remark \\
\hline & Abass et al. ${ }^{21}$ & $\begin{array}{l}\text { Lumbar stabilization for PI in } \\
\text { chronic LBP }\end{array}$ & 0.236 & 0.082 & $48 \%$ & $\mathrm{X}$ \\
\hline & $\begin{array}{l}\text { Adeniyi et } \\
\text { al. }^{26}\end{array}$ & Exercise for pain in Type 2 DM & $<0.05$ & IN & & - \\
\hline & $\begin{array}{l}\text { Adeniyi et } \\
\text { al, }^{10}\end{array}$ & $\begin{array}{l}\text { Exercise improving for SBP in Type } \\
2 \text { DM }\end{array}$ & 0.030 & IN & & - \\
\hline & $\begin{array}{l}\text { Akinola et } \\
\text { al. }{ }^{27}\end{array}$ & $\begin{array}{l}\text { Exercise improving GMF in spastic } \\
\mathrm{CP}\end{array}$ & 0.001 & 0.236 & $9 \%$ & $x$ \\
\hline & Abdulahi, ${ }^{24}$ & CIMT improving MF in stroke & $>0.05$ & 0.348 & $46 \%$ & $\mathrm{x}$ \\
\hline & $\begin{array}{l}\text { Adepoju et } \\
\text { al. }^{28}\end{array}$ & Exercise improving balance in $\mathrm{CP}$ & 0.339 & 0.57 & $58 \%$ & $\mathrm{X}$ \\
\hline & $\begin{array}{l}\text { Ajiboye et } \\
\text { al. } 29\end{array}$ & $\begin{array}{l}\text { Exercise improving walking } \\
\text { capacity in CHF (biventricular) }\end{array}$ & $p<0.05$ & 1.28 & $100 \%$ & $\sqrt{ }$ \\
\hline & $\begin{array}{l}\text { Akodu \& } \\
\text { Akindutire, }\end{array}$ & $\begin{array}{l}\text { Exercise for sleep disturbance in } \\
\text { LBP (NS) }\end{array}$ & 0.030 & 0.6 & $100 \%$ & $\sqrt{ }$ \\
\hline & Aliyu et al. ${ }^{22}$ & Exercise for pain in LBP (NS) & 0.600 & 0.0078 & $85 \%$ & $\sqrt{ }$ \\
\hline & Aweto et al. ${ }^{31}$ & $\begin{array}{l}\text { Exercise for depression score in PL } \\
\text { HIV }\end{array}$ & 0.925 & 0.36 & $100 \%$ & $\sqrt{ }$ \\
\hline & Bello et al. ${ }^{23}$ & $\begin{array}{l}\text { Manual therapy for FVC in lumbar } \\
\text { radiculopathy }\end{array}$ & 0.000 & 0.26 & $46 \%$ & $x$ \\
\hline & $\begin{array}{l}\text { Bello \& } \\
\text { Adeniyi, }{ }^{32}\end{array}$ & $\begin{array}{l}\text { Exercise for pain intensity (VASB) } \\
\text { in LBP }\end{array}$ & 0.020 & 1.93 & $100 \%$ & $\sqrt{ }$ \\
\hline & $\begin{array}{l}\text { Bolarinde et } \\
\text { al. }^{33}\end{array}$ & Exercise for PI in LBP & $<0.001$ & 0.023 & $60 \%$ & $x$ \\
\hline & $\begin{array}{l}\text { Ezema et } \\
\text { al. }{ }^{34}\end{array}$ & Exercise for FBS in Type 2 DM & 0.001 & 0.59 & $100 \%$ & $\sqrt{ }$ \\
\hline & $\begin{array}{l}\text { Ezema et } \\
\text { al. }{ }^{35}\end{array}$ & Exercise for SBP in PL HIV & 0.000 & 2.74 & $100 \%$ & $\sqrt{ }$ \\
\hline & $\begin{array}{l}\text { Fadupin \& } \\
\text { Akinola }^{36}\end{array}$ & Exercise for FBS in Type 2 DM & $p<0.05$ & 0.16 & $100 \%$ & $\sqrt{ }$ \\
\hline & $\begin{array}{l}\text { Fayehun et } \\
\text { al. }^{37}\end{array}$ & $\begin{array}{l}\text { Walking prescription for HBA1c in } \\
\text { Type } 2 \text { DM }\end{array}$ & 0.0150 & 0.035 & $5 \%$ & $x$ \\
\hline & Aweto et al. ${ }^{38}$ & $\begin{array}{l}\text { Incentive spirometry for FVC in } \\
\text { Type } 2 \text { DM }\end{array}$ & 0.9250 & 0.071 & $6 \%$ & $x$ \\
\hline
\end{tabular}




\begin{tabular}{|c|c|c|c|c|c|}
\hline $\begin{array}{l}\text { Idowu \& } \\
\text { Adeniyi }^{39}\end{array}$ & $\begin{array}{l}\text { Graded activity with monitoring for } \\
\text { PI in LBP and Type } 2 \text { DM }\end{array}$ & $<0.001$ & 1.94 & $99 \%$ & $\sqrt{ }$ \\
\hline Ige et al. ${ }^{40}$ & Pulmonary rehab for FEV1 in COPD & $<0.050$ & 2.518 & $100 \%$ & $\sqrt{ }$ \\
\hline $\begin{array}{l}\text { Jegede et } \\
\text { al. }{ }^{41}\end{array}$ & $\begin{array}{l}\text { Exercise for WR in obese } \\
\text { individuals }\end{array}$ & $<0.001$ & 1.17 & $99 \%$ & $\sqrt{ }$ \\
\hline John et al. ${ }^{25}$ & Exercise for SBP in PL HIV & 0.001 & 0.12 & $100 \%$ & $\sqrt{ }$ \\
\hline $\begin{array}{l}\text { Johnson et } \\
\text { al. }^{42}\end{array}$ & McKenzie for PI in LBP & 0.020 & 1.18 & $79 \%$ & $x$ \\
\hline $\begin{array}{l}\text { Lamina et } \\
\text { al. }^{43}\end{array}$ & Exercise for SBP in hypertension & 0.001 & 1.04 & $100 \%$ & $\sqrt{ }$ \\
\hline $\begin{array}{l}\text { Lamina \& } \\
\text { Okoye }^{44}\end{array}$ & $\begin{array}{l}\text { Exercise for lipid profile in } \\
\text { hypertension }\end{array}$ & 0.001 & 0.007 & $57 \%$ & $x$ \\
\hline $\begin{array}{l}\text { Lamina \& } \\
\text { Okoye, }{ }^{45}\end{array}$ & $\begin{array}{l}\text { Moderate intensity training for } \\
\text { SBP in hypertension }\end{array}$ & 0.001 & 1.22 & $100 \%$ & $\sqrt{ }$ \\
\hline $\begin{array}{l}\text { Maduagwu et } \\
\text { al. }^{46}\end{array}$ & Exercise on CD4 in HIV seropositive & 0.917 & 0.023 & $6 \%$ & $x$ \\
\hline Maruf et al. ${ }^{47}$ & Exercise for BP in hypertension & 0.075 & 0.39 & $74 \%$ & $x$ \\
\hline $\begin{array}{l}\text { Mbada et } \\
\text { al. }{ }^{48}\end{array}$ & McKenzie for DBEE in LBP & 0.001 & 0.27 & $100 \%$ & $\sqrt{ }$ \\
\hline $\begin{array}{l}\text { Odebiyi et } \\
\text { al. }^{49}\end{array}$ & $\begin{array}{l}\text { Exercise and massage for QoL of } \\
\text { cancer patient }\end{array}$ & $\underset{\star}{0.001}$ & 0.39 & $100 \%$ & $\sqrt{ }$ \\
\hline $\begin{array}{l}\text { Odole \& } \\
\text { Ojo, } 50\end{array}$ & $\begin{array}{l}\text { Telephone based therapy for PI on } \\
\text { OA }\end{array}$ & 0.001 & 0.16 & $100 \%$ & $\sqrt{ }$ \\
\hline $\begin{array}{l}\text { Ogbutor et } \\
\text { al. }^{51}\end{array}$ & $\begin{array}{l}\text { Exercise for SBP in pre } \\
\text { hypertensives }\end{array}$ & 1.653 & 1.5 & $100 \%$ & $\sqrt{ }$ \\
\hline $\begin{array}{l}\text { Ogwumike et } \\
\text { al. }^{52}\end{array}$ & $\begin{array}{l}2 \text { Exercises for Adiposity in peri } \\
\text { and post menopausals }\end{array}$ & 0.050 & 0.959 & $23 \%$ & $x$ \\
\hline $\begin{array}{l}\text { Ojoawo et } \\
\text { al. }^{53}\end{array}$ & Exercise for PI in LBP & 1.000 & 0.052 & $5 \%$ & $x$ \\
\hline $\begin{array}{l}\text { Ojoawo et } \\
\text { al. }^{54}\end{array}$ & US and massage for PI in LBP & 0.001 & 0.57 & $99 \%$ & $\sqrt{ }$ \\
\hline $\begin{array}{l}\text { Ojoawo et } \\
\text { al. }{ }^{55}\end{array}$ & TOP for PI in cervical radiculopathy & $<0.05$ & 0.53 & $85 \%$ & $\sqrt{ }$ \\
\hline Ojoawo \& & $\begin{array}{l}\text { TOP a1nd traction for NDI in } \\
\text { cervical radiculopathy }\end{array}$ & 0.889 & 0.125 & $42 \%$ & $x$ \\
\hline
\end{tabular}


Olabode, 56

Okonkwo et $\quad$ TENS for PI in injection sciatic pain $\quad 0.001 \quad 0.16 \quad 13 \% \quad X$ al. 57

$\begin{array}{lllllll}\text { Olagbegi et } & \text { Exercise for SQMS in OA } & >0.05 & 0.07 & 100 \% & \sqrt{ }\end{array}$

al. ${ }^{58}$

Olagbegi et $\quad$ Exercise for ADL in OA

al. $^{59}$

$\begin{array}{llll}< & 0.737 \quad 100 \% \quad \sqrt{ }\end{array}$

Onuwe et

al. ${ }^{60}$

Double modality for PP in MSK

$<0.05$

0.293

$24 \%$

X

Lamina \& injuries

Okoye, 61

$\begin{array}{lllllll}\text { Maduagwu et } & \text { Exercise for CD4 cells on in HIV } & 0.002 & 0.82 & 90 \% & \sqrt{ }\end{array}$

al. $^{62}$

Usman et

Combination therapy for $\mathrm{PI}$ in $\mathrm{OA}$

0.001

0.67

$0.67 \quad 100 \% \quad \sqrt{ }$

Exercise for SBP in hypertension

0.001

al. $^{63}$

Mbada et

Exercise for FAB in LBP

al. ${ }^{64}$

Lamina \&

Interval training program for SBP in

Okoye ${ }^{20}$

hypertension

Aweto et al. ${ }^{65}$ Incentive spirometer for FEV in

asthma

Kaka et al. ${ }^{66}$ Exercise for VAS in NS-neck pain

$0.001 \quad 1.267 \quad 100 \% \quad \sqrt{ }$

Maharaj \& $\quad$ Exercise for FBS in type 2 DM

0.002

0.122

$21 \% \quad x$

Nuhu, ${ }^{67}$

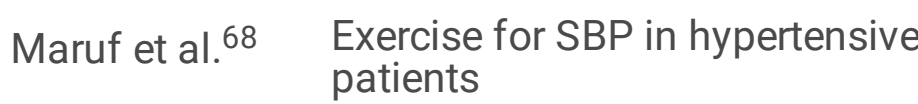

$\begin{array}{llll}0.001 & 0.751 & 98 \% & \sqrt{ }\end{array}$

Ezema et $\quad$ Exercise for FBS in type 2 DM

$<0.01$

$-1.281$

$98 \%$

al. $^{69}$

Ojoawo et

VOP for RMDQ in chronic LBP

0.692

0.549

$68 \%$

al. 70

Ojoawo et

Exercise for VAS in knee OA

$<0.01$

0.386

$87 \%$

al. $^{71}$

Onigbinde et Exercise for dynamic B in stroke

0.040

0.938

$95 \%$

al. ${ }^{19}$

Onigbinde et IQS for RMx in OA

0.001

0.644

$89 \%$

al. $^{72}$ 
$X$ : finding is probably not a reflection of true effect; $\sqrt{ }$ : finding is probably a reflection of true effect; IN: information not available. DM: diabetes mellitus; CP: cerebral palsy; CIMT: Constraint-induced movement therapy; CHF: congestive heart failure;WR: weight reduction; LBP (NS): Low back pain (non-specific); SBP: Systolic blood pressure; Type 2 DM: Type 2 diabetes mellitus; (G) MF: (Gross) motor function; CHF: Chronic heart failure; (PL) HIV: (People living with) Human Immuno-deficiency virus; FVC; Forced vital capacity; VAS (B): Visual analogue scale (back); PI: Pain intensity; FBS: Fasting blood sugar; HBA1c: Glycosylated hemoglobin; DBEE: dynamic back extensors endurance; COPD: Chronic obstructive pulmonary disease; QoL: Quality of life; OA: Osteoarthritis; DRPEE: Dynamic Back Endurance Exercise; US: Ultrasound; SQS: static quadriceps muscle strength; TOP: Transverse Oscillatory pressure; ADL: Activity of daily living; FAB: Fear-Avoidance Beliefs IQS- isometric quadriceps strengthening SWD- short wave diathermy RM- Repetitive maximum RMDQ- Roland-Morris Disability Questionnaire; FPG

\section{Discussion}

This review was conducted to characterize and critique physiotherapy interventional research in Nigeria. Following the literature search, the majority of the studies were excluded for being non-interventional, leaving only 56 studies that met inclusion criteria. This is a poor output compared with the expected volume of clinical trials from postgraduate Physiotherapy research, particularly PhDs, in the country. This suggests that clinical trials are an uncommon engagement among physiotherapist researchers in Nigeria. However, the number may reflect the volume of unpublished experimental theses and dissertations as well as the numbered published in fair to high impact journals indexed with Medline, Pubmed, and Cumulative Index for Nursing, Allied Health and Life Sciences, Academic Search Complete. This collaborates with the findings of Hamzat and Amusat ${ }^{9}$ and Adeniyi et al. ${ }^{10}$ Hazmat reported a low level of participation in clinical research among Nigerian physiotherapists, while Adeniyi et al. ${ }^{10}$ reported crosssectional design to be most prevalent among undergraduate students. Research output is a required criterion for the promotion of University academics in Nigeria. However, whether a study is a clinical experiment or a once-off observation study does not make a difference in the appraisal score for promotion of academics, thus disfavoring the chances for more rigorous and costly clinical experiments. ${ }^{74,75}$

Of the clinical experiments, randomized control trials were the most prevalent. This is a desirable outcome because RCTs form the gold standard design for responsible conduct of clinical research especially ones seeking the development of clinical intervention and innovation. ${ }^{76,77}$ Interestingly, the fact that only a few of the RCTs preserved the integrity of randomization through intention-to-treat analysis is undesirable. Randomization can greatly reduce the unintentional bias and confounding effects that may exist between the control group and the intervention group. Randomization ensures the later use of probability theory to perform the statistical analysis. ${ }^{78} \mathrm{It}$ is important to make sure the control 
and treatment have the same conditions in various aspects. ${ }^{79}$ Contrary to this outcome of the study, Adeniyi et al. ${ }^{10}$ found cross-sectional observational studies to be the most prevalent. However, the choice of cross-sectional designs over RCT designs may be due to the limited time allocated (i.e., having less than 6 months) for the completion of undergraduate project work.

We found a fair proportion of statistical analysis inappropriate in a fair proportion of the studies, with lack of covariate analysis and lack of normality test being the major reasons. This indicates a fair degree of inadequacy of statistical education among Physiotherapy researchers in Nigeria. This supports the advocacy for statistical education among Nigeria research, ${ }^{80}$ as knowledge of statistics is essential for biomedical research and innovation. Although this is the first methodical review appraising statistical application among Nigerian clinical research, the finding collaborates that of Yan et al. ${ }^{79}$ According to Yan et al. ${ }^{79}$ common statistical omissions or malpractices include ignoring the sample size and data distribution, incorrect summarization measurement, wrong statistical test methods especially for repeated measures, ignoring the assumption for t-test or ANOVA test, failing to perform the adjustment for multiple comparisons. Confounds have been known to introduce bias in research studies. ${ }^{81}$ In interventional research, the presence of significant bias raises the question of whether the outcomes are credible and recommended for application in the clinical setting for the management of patients and clients. ${ }^{79,81}$ Without the proper application of statistical methods, the risk increases and the data collection suffers from additional costs and efforts; the analysis of research efforts gives suboptimal results and eventually, wrong decisions can be taken. ${ }^{80}$

Interestingly, most of the studies were of suboptimal quality. This collaborates with the finding endorsed by the UK Department for International Development, ${ }^{12}$ which revealed a remarkable prevalence of lowquality research in Nigeria. Factors associated with poor-quality research in Nigeria include weak national research funding capacity, and lack of mechanisms for research quality evaluation. ${ }^{12}$ Quality appraisal assessment is important in permitting researchers to draw effective conclusions and broader inferences concerning the primary study. ${ }^{82}$ Furthermore, our study findings align with that of Hassan and Schaffer ${ }^{83}$ which reported poor quality of clinical research and science in Africa. Another study by Garba and Saidu, ${ }^{14}$ found that the lack of high-quality research in Nigeria constitutes an impediment to the growth and development of the country. The fraction of resources imputed into research output is minimal and lack of funding, equipment and mentoring are the prominent reasons for the poor quality of research. ${ }^{14}$ Therefore, addressing these putative barriers will improve the quality of Nigerian's research; increase the translation of clinical research into impactful products and decisions. ${ }^{14,84,85}$

More than half of the studies included studies were sufficiently powered, with $50 \%$ being overtly powered. This is a desirable outcome, however, over $30 \%$ of the clinical experiments are underpowered thereby resulting in an average statistical power of $71 \%$. This is undesirable and indicates the need for statistical consultation (or inclusion of a biostatistician) in clinical departments across Nigerian academic institutions. This is because a low statistical power has a reduced chance of detecting a true effect and the chance that a statistically significant result reflects a true effect. Similarly, about half of the studies 
were overtly powered and this reflects wastefulness ${ }^{86}$ in the conduct of clinical physiotherapy research in Nigeria. Furthermore, possession of adequate sample size is a good trait of quality clinical research, however, the incongruence between study quality (mostly suboptimal) and power (mostly sufficient) in our review reflects a lack of statistical consultation or expertise among Physiotherapists researchers in Nigeria. ${ }^{80}$ Given this incongruence, the findings that most of the studies observed medium to large effect cast doubt on the efficacy of Physiotherapy interventions as reported in the Nigerian studies, thus requiring further investigation.

Assessment of effect size otherwise known as the magnitude of treatment effects revealed that Physiotherapeutic interventions as utilized in this study are largely effective for the disorders indicated in the studies. This is consistent with results obtained by Herbert et al. ${ }^{87}$ who found various physiotherapy interventions-exercise and massage yielded positive health outcomes in the patient population studied. Our review, show that exercise was the most important intervention or treatment modality employed among Nigerian Physiotherapists. This shows that exercise as a mainstay physiotherapy intervention is of significant benefits. This is in keeping with an evidence-based recommendation as enshrined in clinical practice guidelines for the management of low-back pain. ${ }^{88,89}$ Also, the findings that electrotherapy modalities (usually used for pain) possessed nil to medium effect $(21,53,57)$ reflects clinical practices guidelines recommendations to avoid electrotherapy modalities for the management of an orthopaedic condition like low-back pain because they have found to be ineffective. ${ }^{88,89}$ Despite this finding, the incongruence between study power and magnitude of treatment effects in most of the studies included in this review casts doubt on the efficacy of physiotherapy intervention for the health outcomes studied. Hence, there is a need for the pursuit of excellence when conducting further clinical Physiotherapy research as this is the only way to make research count. The fact that that we may not have included all eligible studies constitutes a limitation. However, we made efforts to search relevant databases.

\section{Conclusions}

Of clinical experiments, clinical trial occupies the top row in the Nigerian physiotherapy community. The methodological quality of physiotherapy research in Nigeria is suboptimal. The magnitude of effects of Physiotherapy interventions varies from nil effect to large effect. Exercise is the most prevalent and effective intervention, while electrotherapeutic modalities are the least important.

\section{Declarations}

Ethics approval and consent to participate: Not applicable

Consent for publication: Not applicable

\section{Availability of data and material}

Review data is available from the corresponding author on request. 


\section{Competing interest}

No potential conflict of interest to this article was reported

Funding: None

\section{Authors' contributions}

Martins Nweke and Emeriewen Ejirogheneconceived the study. Martins Nweke conducted the searches and Emeriewen Ejiroghenedownloaded the studies and conducted initial screening under the supervision of Martins Nweke. Martins and Emeriewen Ejirogheneran the analysis. Henrietta .O. Fawoleformatted conducted quality appraisal and the reference list. Mshunqane Nombeko read through and critique the manuscript.

Acknowledgements: The authors thank the Head of Department of the University of Benin, Prof Kayode Oke for proving us with moral supports.

\section{References}

1. Ghaemi SN, Goodwin FK. The ethics of clinical innovation in psychopharmacology: Challenging traditional bioethics. Philosophy, Ethics, and Humanities in Medicine. 2007; 2:26.

2. Barbosa D. The importance of clinical research in improving health care practice. Acta Paulista de Enfermagem. 2010;23:viii

3. Cascella M, Rajnik M, Cuomo A, Dulebohn SC, di Napoli R. Features, Evaluation and Treatment Coronavirus (COVID-19). StatPearls Publishing; 2020. https://www.ncbi.nlm.nih.gov/books/NBK554776/

4. Gostin LO, Nass S. Reforming the HIPAA privacy rule: safeguarding privacy and promoting research. Journal of American Medical Association. 2009; 301:1373-1375.

5. Bates DW, Leape LL, Cullen DJ, et al. Effect of computerized physician order entry and a team intervention on prevention of serious medication errors. Journal of American Medical Association. 1998; 280:1311-1316.

6. National Research Council. Advancing the Nation's Health Needs: NIH Research Training Programs. Washington DC: National Academies Press. https://www.ncbi.nlm.nih.gov/books/NBK22631/; 2005. Accessed July 31, 2021.

7. Food and Drug Administration. Center for Drug Evaluation and Reseach, guidance for industry, investigators,and institutional review boards. US Food and Drug Administration. https://www.fda; 2020.

8. Oke KI. 'The past, the present and the future of physiotherapy in Nigeria'. Guest Lecture at University of Benin Student Association Health week. 2019. 
9. Hamzat TK, Amusat NT. Belief and participation with clinical physiotherapists in research. South African Journal of Physiotherapy. 2002; 58:32-34.

10. Adeniyi AF, Ekechukwu NE, Umar L, Ogwumike OO. Research profile of Physiotherapy undergraduates in Nigeria. Education for Health. 2013; 26:15-20.

11. Fosci M, Loffreda L, Chamberlain A, Naidoo N. Assessing the needs of the research system in Nigeria. Report for the SRIA programme.

https://assets.publishing.service.gov.uk/media/5ef4ad5ee90e075c5cc9cc7e6/; 2019.

12. Balogun JA, Aka P,Balogun AO, Obajuluwa VA. A phenomenological investigation of the first two decades OF university-based Physiotherapy education in Nigeria. Cogent Medicine. 2017; 4:1301183.

13. Garba B, Saidu B. Biomedical research in Nigeria: realities and misconceptions. Future Science OA. 2020; 6:FS0475.

14. Tricco A, Lillie E, Zarin W, et al. PRISMA extension for scoping reviews (PRISMA-ScR): Checklist and explanation. Annals of Internal Medicine. 2018; 169:467-473.

15. Maher CG, Sherrington C, Herbert RD, Moseley AM, Elkins M. Reliability of the PEDro scale for rating quality of randomized controlled trials. Physical Therapy. 2003; 83:713-21.

16. Higgins JPT, Green S. Cochrane handbook for systematic reviews of interventions version 5.1.0 [updated March 2011]. Cochrane Collaboration. 2011.

17. Borenstein M, Hedges LV, Higgins JPT, Rothstein HR. Introduction to meta-analysis. West Sussex: John Wiley \& Sons, Ltd; 2009.

18. Lenhard DW. Computation of different effect sizes like $d, f, r$ and transformation of different effect sizes. Psychometrica. https://www.psychometrica.de/effect_size.html; 2019. Accessed August 2, 2021.

19. Onigbinde AT, Awotidebe T, Awosika H. Effect of 6 weeks wobble board exercises on static and dynamic balance of stroke survivors. Technology and Health Care. 2019; 17:387-392.

20. Lamina S, Okoye CG, Hanif SM. Randomised controlled trial: Effects of aerobic exercise training programme on indices of adiposity and metabolic markers in hypertension. Journal of Pakistan Medical Association. 2013; 63:680-687.

21. Abass AO, Alli AR, Olagbegi OM, Christie CJ, Bolarinde SO. Effects of an eight-week LUMBAR Stabilization exercise programme on selected variables of patients with chronic low back pain. Bangladesh Journal of Medical Science. 2020; 19:467-474.

22. Aliyu FU, Wasiu AA, Bello B. Effects of a combined lumbar stabilization exercise and cognitive behavioral therapy on selected variables of individuals with non-specific low back pain: A randomized clinical trial. Fisioterapia. 2018; 40:257-264.

23. Bello B, Danazumi, MS, Kaka B. Comparative effectiveness of 2 manual therapy techniques in the management of lumbar radiculopathy: A randomized clinical trial. Journal of Chiropractic Medicine. $2019 ; 18: 253-261$. 
24. Abdullahi A. Effects of number of repetitions and number of hours of shaping practice during constraint-induced movement therapy: A randomized controlled trial. Neurology Research International. 2018; 5496408.

25. John D, Tella BA, Olawale OA, John JN, Adeyemo TA, Okezue OC. Effects of a 6-week aerobic exercise programme on the cardiovascular parameters, body composition, and quality of life of people living with human immune virus. Journal of Exercise Rehabilitation. 2018; 14:891-898.

26. Adeniyi AF, Fasanmade AA., Sanya AO, Borodo M. Neuromusculoskeletal disorders in patients with type 2 diabetes mellitus: outcome of a twelve-week therapeutic exercise programme. Nigerian Journal of Clinical Practice. 2010; 13:403-408.

27. Akinola Bl, Gbiri CA, Odebiyi DO. Effect of a 10-Week Aquatic Exercise Training Program on Gross Motor Function in Children with Spastic Cerebral Palsy. Global Pediatric Health. 2019; 6:1-7.

28. Adepoju F, Hamzat T, Akinyinka O. Comparative Efficacy of Progressive Resistance Exercise and Biomechanical Ankle Platform System on Functional Indices of Children with Cerebral Palsy. Ethiopian Journal of Health Sciences. 2017; 27:11-16.

29. Ajiboye OA, Anigbogu CN, Ajuluchukwu JN, Jaja SI. Exercise training improves functional walking capacity and activity level of Nigerians with chronic biventricular heart failure. Hong Kong Physiotherapy Journal. 2015; 33:42-49.

30. Akodu AK, Akindutire OM. The effect of stabilization exercise on pain-related disability, sleep disturbance, and psychological status of patients with non-specific chronic low back pain. Korean Journal of Pain. 2018; 1:199-205.

31. Aweto HA, Aiyegbusi Al, Ugonabo AJ, Adeyemo TA. Effects of aerobic exercise on the pulmonary functions, respiratory symptoms and psychological status of people living with HIV. Journal of Research in Health Sciences. 2016; 16:17-21.

32. Bello B, Adeniyi AF. Effects of lumbar stabilisation and treadmill exercise on function in patients with chronic mechanical low back pain. International Journal of Therapy and Rehabilitation. 2018; 25:493-499.

33. Bolarinde SO, Adegoke B, Ayanniyi O, Olagbegi O. Effects of Stretching Exercises on Pain and Functional Disability in Quarry Workers with Work-related Low Back Pain. Journal of Health and Safety, Research and Practice. 2017; 9:3-11.

34. Ezema Cl, Onwunali AA, Lamina S, Ezugwu UA, Amaeze AA, Nwankwo, MJ. Effect of aerobic exercise training on cardiovascular parameters and CD4 cell count of people living with human immunodeficiency virus/acquired immune deficiency syndrome: A randomized controlled trial. Nigerian Journal of Clinical Practice. 2014; 17:543-548.

35. Ezema $\mathrm{Cl}$, Omeh $\mathrm{E}$, Onyeso OKK, et al.The effect of an aerobic exercise programme on blood glucose level, cardiovascular parameters, peripheral oxygen saturation, and body mass index among Southern Nigerians with type 2 diabetes mellitus, undergoing concurrent sulfonylurea and metformin treatment. Malaysian Journal of Medical Sciences. 2019; 26:88-97. 
36. Fadupin GT, Akinola OA. Importance of accurate food measurement and physical exercise on BMI and glycaemic control in obese type 2 diabetic patients. African Journal of Diabetes Medicine. 2011; 19:20-22.

37. Fayehun AF, Olowookere 00, Ogunbode AM, Adetunji AA, Esan A. Walking prescription of 10000 steps per day in patients with type 2 diabetes mellitus: A randomised trial in Nigerian general practice. British Journal of General Practice. 2018; 68:e139-e145.

38. Aweto HA, Obikeh EO, Tella BA. Effects of incentive spirometry on cardiopulmonary parameters, functional capacity and glycemic control in patients with Type 2 diabetes. Hong Kong Physiotherapy Journal. 2020; 40:121-132.

39. Idowu OA, Adeniyi AF. Efficacy of Graded Activity with and without Daily-Monitored-Walking on Pain and Back Endurance among Patients with Concomitant Low-Back Pain and Type-2 Diabetes: A Randomized Trial. Ethiopian Journal of Health Sciences. 2020; 30:233-242.

40. Ige OM, Olarewaju RK, Lasebikan VO, Adeniyi YO. Outpatient pulmonary rehabilitation in severe chronic obstructive pulmonary disease. Indian Journal of Chest Diseases and Allied Sciences. 2010; 52:197-201.

41. Jegede JA, Adegoke BOA, Olagbegi OM. Effects of a Twelve-Week Weight Reduction Exercise Programme on Selected Spatiotemporal Gait Parameters of Obese Individuals. Journal of Obesity 2017; 4193256

42. Johnson OE, Adegoke BOA, Ogunlade SO. Comparison of four physiotherapy regimens in the treatment of long-term mechanical low back pain. Journal of the Japanese Physical Therapy Association. 2010; 13:9-16.

43. Lamina S, Okoye G. Effect of interval training programme on pulse pressure in the management of hypertension: A randomized controlled trial. African Health Sciences. 2013; 13:571-578.

44. Lamina S, Okoye G. Effects of aerobic exercise training on psychosocial status and serum uric acid in men with essential hypertension: A randomized controlled trial. Annals of Medical and Health Sciences Research. 2012; 2:161-168.

45. Lamina S, Okoye G. Therapeutic effects of a moderate intensity interval training program on the lipid profile in men with hypertension: A randomized controlled trial. Nigerian Journal of Clinical Practice. 2012; 15:42-47.

46. Maduagwu SM, Gashau W, Balami A, et al. Aerobic Exercise Improves Quality of Life and CD4 Cell Counts in HIV Seropositives in Nigeria. Journal of Human Virology \& Retrovirology. 2017; 5.

47. Maruf FA, Akinpelu AO, Salako BL. Effects of aerobic exercise and drug therapy on blood pressure and antihypertensive drugs: a randomized controlled trial. African Health Sciences. 2013; 13:1-9.

48. Mbada CE, Ayanniyi O, Ogunlade SO, Orimolade EA, Oladiran AB, Ogundele AO. Rehabilitation of back extensors' inhibition in patients with long-term mechanical low-back pain. ISRN Rehabilitation 2013; 928956.

49. Odebiyi DO, Aborowa AT, Sokunbi OG, Aweto HA, Ajekigbe AT. Effects of exercise and oedema massage on fatigue level and quality of life of female breast cancer patients. European Journal of 
Physiotherapy. 2014; 16: 238-245.

50. Odole AC, Ojo OD. A Telephone-based Physiotherapy Intervention for Patients with Osteoarthritis of the Knee. International Journal of Tele-rehabilitation. 2013; 5:11-20.

51. Ogbutor GU, Nwangwa EK, Uyagu DD. Isometric handgrip exercise training attenuates blood pressure in prehypertensive subjects at $30 \%$ maximum voluntary contraction. Nigerian Journal of Clinical Practice. 2019; 22:1765-1771.

52. Ogwumike 0O, Arowojolu AO, Sanya AO. Effects of a12-week endurance exercise program on adiposity and flexibility of Nigerian perimenopausal and postmenopausal women. Nigerian Journal of Physiological Sciences. 2011; 26:199-206.

53. Ojoawo AO, Hassan A, Olatokunbo M, Olaogun B, Johnson EO, Mbada CE. Comparative effectiveness of two stabilization exercise positions on pain and functional disability of patients with low back pain. Journal of Exercise Rehabilitation. 2017; 13:363-371.

54. Ojoawo AO, Malomo EO, Olusegun EO, Olaogun BMO. Effects of pulse ultrasound and kneading massage in managing individual with incessant pain at lower region of back using random allocation. Journal of Exercise Rehabilitation. 2018; 14:516-522.

55. Ojoawo AO, Olabode A, Esan O, Badru A, Odejide S, Arilewola B. Transverse oscillatory pressure in management of cervical radiculopathy: A randomised controlled study. Hong Kong Physiotherapy Journal. 2016; 34:19-26.

56. Ojoawo AO, Olabode AD. Comparative effects of transverse oscillatory pressure and cervical traction in the management of cervical radiculopathy: A randomised controlled study. Hong Kong Physiotherapy Journal. 2018; 48:149-160.

57. Okonkwo UP, Ibeneme SC, Ihegihu EY, et al. Effects of transcutaneous electrical nerve stimulation in the Management of Post-Injection Sciatic Pain in a non-randomized controlled clinical trial in Nnewi, Nigeria. BMC Complementary and Alternative Medicine. 2018; 18:310-320.

58. Olagbegi OM, Adegoke BO, Odole AC. Effectiveness of three modes of kinetic-chain exercises on quadriceps muscle strength and thigh girth among individuals with knee osteoarthritis. Archives of Physiotherapy. 2017; 7:9-19.

59. Olagbegi OM, Adegoke BO, Odole AC. Effectiveness of combined chain exercises on pain and function in patients with knee osteoarthritis. Bangladesh Journal of Medical Science. 2016; 15:178188.

60. Onuwe HAK, Amadi K, Odeh SO. Comparison of the therapeutic efficacy of double-modality therapy, phonophoresis and cryotherapy in the management of musculoskeletal injuries in adult Nigerian subjects. Nigerian Journal of Physiological Sciences. 2013; 28:153-158.

61. Lamina S, Okoye GC. Therapeutic effect of continuous exercise training program on serum creatinine concentration in men with hypertension: A randomized controlled trial. Ghana Medical Journal. 2014; 48:135-142.

62. Maduagwu SM, Kaidai A, Gashau W, et al. Effect of Aerobic Exercise on CD4 Cell Count and Lipid Profile of HIV Infected Persons in North Eastern Nigeria. Journal of AIDS and Clinical Research. 2015; 
6.

63. Usman Z, Maharaj SS, Kaka B. Effects of combination therapy and infrared radiation on pain, physical function, and quality of life in subjects with knee osteoarthritis: A randomized controlled study. Hong Kong Physiotherapy Journal. 2019; 39:133-142.

64. Mbada CE, Ayanniyi O, Ogunlade SO. Comparative efficacy of three active treatment modules on psychosocial variables in patients with long-term mechanical low-back pain: a randomized controlled trial. Archives of Physiotherapy. 2015; 5:10-18.

65. Aweto HA, Aiyegbusi Al, Olaniyan ZO. A comparative study of the effects of incentive spirometry and diaphragmatic resistance training on selected cardiopulmonary parameters in patients with Asthma. Romanian Journal of Physical Therapy. 2017; 23:25-34

66. Kaka B, Ogwumike OO, Adeniyi AF, Maharaj SS,Ogunlade SO, Bello B. Effectiveness of neck stabilization and dynamic exercises on pain intensity, depression and anxiety among patients with non-specific neck pain: a randomized controlled trial. Scandinavian Journal of Pain. 2018; 18:321331.

67. Maharaj SS, Nuhu JM. Rebound exercise. A beneficial adjuvant for sedentary non-insulin-dependent type 2 diabetic individuals in a rural environment. Australian Journal of Rural Health. 2016; 24:123129.

68. Maruf FA, Akinpelu AO, Salako BL, Akinyemi JO. Effects of aerobic exercise dance training on blood pressure in individuals with uncontrolled hypertension on two antihypertensive drugs: a randomized clinical trial. Journal of the American Society of Hypertension. 2016; 10:336-345.

69. Ezema $\mathrm{Cl}$, Okwuchukwu CK Amarachukwu CN, et al. Effect of a single bout interval aerobic exercise on blood glucose level in type 2 diabetes mellitus patients. Indian Journal of Physiotherapy and Occupational Therapy. 2019; 13:206-211.

70. Ojoawo AO, Olaogun MO, Odejide SA, Badru AA. Effect of vertical oscillatory pressure on disability of patients with chronic mechanical low back pain using Roland Morris disability questionnaire. Tanzania Journal of Health Research. 2013; 15.

71. Ojoawo AO, Olaogun MOB, Hassan MA. Comparative effects of proprioceptive and isometric exercise on pain intensity and difficulty in patients with knee osteoarthritis: A randomised control study. Technology and Health Care. 2016; 24:853-863.

72. Onigbinde AT, Ajiboye RA, Bada Al, Isaac SO. Inter-limb effects of isometric quadriceps strengthening on untrained contra-lateral homologous muscle of patients with knee osteoarthritis. Technology and Health Care. 2017; 25:19-27.

73. Onigbinde AT, Adebowale AC, Ojoawo AO, Odejide AS, Arilewola B. Comparative effects of pulsed and continuous short wave diathermy on pain and selected physiological parameters among subjects with chronic knee osteoarthritis. Technology and Health Care. 2013; 21:433-440.

74. Pluye P, Gagnon MP, Griffiths F, Johnson-Lafleur JA. Scoring system for appraising mixed methods research, and concomitantly appraising qualitative, quantitative and mixed methods primary studies in mixed studies reviews. International Journal of Nursing Studies. 2009; 46:529-546. 
75. Lee YK, Shin ES, Shim JY, Min KJ. Kim JM, Lee SH. Executive committee for CPGs; Koran Academy of Medical Sciences. Developing a scoring guide for appraisal of guidelines for research and evaluation II instrument in Korea: a modified Delphi consensus process. Journal of Korean Medical Sciences. 2013; 28:190-194.

76. Zabor EC, Kaizer AM, Hobbs BP. Randomised controlled trials. Chest. 2020; 158:S79-S87

77. Lim C-Y, In J. Randomization in clinical studies. Korean Journal of Anesthesiology. 2019; 72:221232.

78. Bajwa SJS. Basics, common errors and essentials of statistical tools and techniques In Anesthesiology research. Journal of Anaesthesiology Clinical Pharmacology. 2015; 31:547.

79. Yan F, Robert M, Li Y. Statistical methods and common problems in medical or biomedical science research. International journal of physiology, pathophysiology and pharmacology. 2017; 9:157-163

80. Adelodun OA, Awe 00. Statistics education in Nigeria: A recent survey. Journal of Education and Practice. 2013; 4:214-220.

81. Wallach JD, Serghiou S, Chu L, et al. Evaluating of confounding in epidemiologic studies assessing alcohol consumption on the risk of ischemic heart disease. BMC Medical Research Methodology. 2020; 20:64-73.

82. Protogerou C, Hagger MS. A case for a study quality appraisal in survey studies in psychology. Frontier in Psychology. 2019; 9:2788.

83. Hassan MHA, Schaffer D. The third world academy of sciences: celebrating two decades of progress. Current Science. 2001; 81:920-926.

84. Okoduwa SIR, Abe JO, Samuel BI, et al. Attitudes, perception ad barriers to research and publishing among research and teaching staff in a Nigerian research institute. Frontiers in Research Metric and Analytics. 2018; 3:26-35.

85. Nwagu W. Mapping of landscape of biomedical literature in Nigeria since 1979. Learned Publishing. 2005; 18:200-211.

86. Case LD, Ambrosius WT. Power and sample size. Methods in Molecular Biology. 2007; 404:377-408.

87. Herbert RD, Maher CG, Moseley AM, Sherrington C. Effective physiotherapy. BMJ. 2001; 323:788-790.

88. de Campos TF. Low back pain and sciatica in over 16s: assessment and management NICE guideline (NG59). Journal of Physiotherapy. 2017; 63:120.

89. Staal JB, Hendriks EJM, Heijmans M, et al. KNGF clinical practice guidelines for physical therapy in patients with low back pain. Amersfoort: The Royal Dutch Society for Physical Therapy (KNGF). 2013.

\section{Figures}




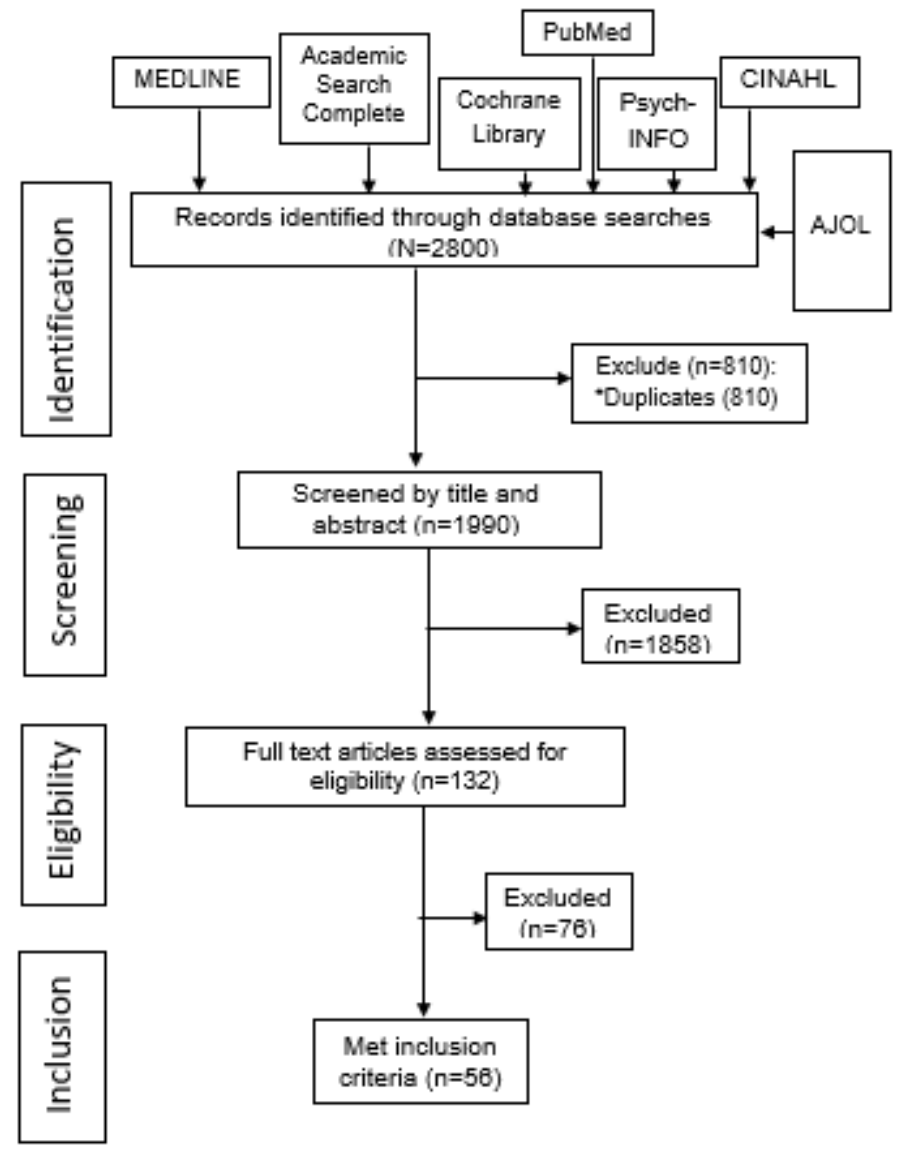

Figure 1: PRISMA flow diagram of the systematic review of articles characterizing and appraising the quality of physiotherapeutic interventional research in Nigeria (2009-2020)

\section{Figure 1}

See image above for figure legend

\section{Supplementary Files}

This is a list of supplementary files associated with this preprint. Click to download.

- Appendixl.docx 